\title{
Stage II Urethral Cancer AJCC v7
}

National Cancer Institute

\section{Source}

National Cancer Institute. Stage II Urethral Cancer AJCC v7. NCI Thesaurus. Code C6198.

Stage II includes: T2, N0, M0. T2: Tumor invades any of the following: corpus

spongiosum, prostate, periurethral muscle. NO: No regional lymph node metastasis. MO:

No distant metastasis. (AJCC 7th ed.) 